\title{
SELECTING SUITABLE DRAINAGE PATTERN TO MINIMIZE FLOODING IN SANGERE VILLAGE USING GIS AND REMOTE SENSING
}

T. ABUBAKAR, E. A. EZRA ANDC. MOHAMMED

\begin{abstract}
Water shed analysis is a geographic information system (GIS) based technique designed to model the way surface water flows on the earth surface. This was the method adopted to select suitable drainage pattern to minimized flood in some parts of sangere. The process of watershed computes the local direction of flow and defines the stream network and the areas drained by particular system. The data used for these calculation (that is, aspect, slope and height differences) are derived from the digital elevation model (DEM) of the area, which was first generated from spot heights obtained from the ground survey using Total Station. ILWIS 3.3 software package was employed in the production of slope and aspect map from which watershed map was produced. The result shows the production of watershed for build up area and suitable drainage network. The research recommended watershed analysis for the control of flood in sangere and the construction of side drainages along the streets.
\end{abstract}

KEY WORDS: Watershed, Aspect, Slope, Drainage, Flood.

\section{INTRODUCTION}

Among the various natural resources that exist on earth, land is one of the basic natural resources that require total preservation and management for the sustainable survival of man on it. In most parts of the world, especially in developing countries, the problems of flooding are rapidly growing. Rainfall is seen as a major cause of flooding, and this also includes human interference as a joint causative factor; Akintola(1978). Flooding result when runoff streams inflows makes a stream full to capacity and also to low infiltration capacity.

There is the need to explore new approach in solving flooding problems by employing watershed analysis through the use of remote sensing and geographic information system (GIS). Watershed analysis refers to the process of using digital elevation model (DEM) and raster data operation to delineate Watershed and to derive topographic features such as stream and drainage networks. Traditionally Watershed boundaries are drawn manually on topographic map, the analyst uses these to determine where there is a water divide. But Watershed analysis is a process of formulation and carrying out of a course of action involving modification of the natural system of Watershed to achieve specific objectives. There is therefore the need to explore new approaches in solving flood problems by employing Watershed analysis through the use of remote sensing and geographic information system. Sangere village serves as an off campus settlement to the majority of students of the modibbo adama University of Technlogy, Yola. It does not have a single functional drainage system due to unplanned layout, it only have a network of water in random direction depending on the topographic nature of the area which makes the lower level of the area to be water logged and marshy. The affected area remains water logged for a very long period of time and this creates problem to the roads and residence of the village. But with good planning of drainage system within and around the village, will minimize to a great extend the problem of flooding and erosion.

This research work is aimed at selecting suitable drainage pattern to minimize the effect of flood hazard using the application of Watershed analysis and this would be achieved through the following objectives.

a. Design the digital elevation model (DEM) of the area

b. Determine the fill DEM to determine the flood direction

c. Delineation of the Watershed of the study area using Area base analysis for Watershed analysis.

T. Abubakar, Department of Surveying and Geoinformatic, Modibbo Adama University of Technology, yola, Adamawa State, Nigeria

E. A. Ezra, Department of Surveying and Geoinformatic, Modibbo Adama University of Technology, yola, Adamawa State, Nigeria

C. Mohammed, Department of Surveying and Geoinformatic, Modibbo Adama University of Technology, yola, Adamawa State, Nigeria 
Sangere is a residential and commercial area; it has influx of people coming in and going out on daily bases, in addition to the movement of staff and students of Modibbo Adama University of Technology, Yola. But the issue of flooding has continue to serve as a setback to the village especially during the raining season; whereby water use to overflow into residential houses within the lower elevation of the area thereby creating large scale damage to properties, and sometimes, water borne diseases such as cholera epidemics which may results in lost of lives (John et al 2012). It is hoped that, with the derivation of filled DEM, flow direction, flow accumulation, stream networking and finally, the area base Watershed map will help in carrying out some analysis, which will indicate at what slope and to what dept which will make a suitable drainage pattern selection that if fully implemented will solve the problem of flooding in the study area.

A Watershed is an area that drains surface water to a common outlet; it is a hydrologic unit that is often used for management and planning of Watershed boundaries is typically based on a digital Elevation model (DEM). The DEM is regarded as a numerical model of the earth surface in which the third dimension maybe some quantity other than the height. E.g temperature, pressure, gravity value etc (Datta, 2003).

The Environmental Protection Agency's (EPA's) Office of Wetlands, Oceans, and Watersheds (OWOW) develop a comprehensive Watershed Analysis and Management (WAM) that addresses watershed management issues. The main objective is to produce a customer-tailored watershed analysis and management framework that includes geographic-specific analytical assessment methods and application techniques for addressing a wide range of environmental issues such as flooding. Typical problems addressed by the WAM approach include the impact of timber operations on erosion, water quality, and fish habitat and the impacts of various land use plans on pollutant runoff. The cause of flooding is many in numbers and varied, but depends on the relief, climate, vegetation cover, soil and geology. of the particular area of interest. Mazumber, (1983) mentioned that, flood usually occurs due to poor drainage system within and around the area in question, and may occur when there is a heavy downpour within a short period of time resulting in rainfall excess, so heavy that the existing drainage capacity is not adequate to take care of it, and there will be stagnation of surface runoff for some period leading to flooding. Charley (1989), state that, the relationship between subsurface and geology has been investigated and it has been observed that the occurrence and movement of surface water are related to geological structure of the particular area. The geology of the study area is underlain by Albium-Aptian Bima Sandstone and recent river Alluvium (Ishaku 2011). Wisters and Brater (1996), identified that all floods are primarily due to surface runoff and this has been influenced by the nature of the soil in the area, any drainage basin with soil imperious that its infiltration capacity is never exceed is rarely subjected to flood. Watershed is a hydrologic unit that is often used for the
Management and planning of natural resources, therefore, an important application of watershed analysis is in the area of watershed management, thus watershed management approaches the organization and planning of human activities on a watershed by recognizing the interrelationship among land use, soil and water as well as linkages between upland and downstream areas; Bhaskar and krisha, (2004). Another application of watershed analysis is to provide the necessary inputs for hydrological modeling Charley (1989).

Dadson and Li (1999), in San Diego USA, compared the result of flood plain mapping for an actual channel using the traditional (map or paper based) and automated, (Geographical Information Systen (GIS) and Triangulated Irregular network (TIN)). The GIS method uses the Gls stream Pro-software and a careful record as maintained in the task. The result indicates that, GIS flood plains mapping provided significant improvement in efficiency for many task involved in plain computations and mapping. In this researched work, the researcher, utilized the already existing topographic map of the study area, Digital elevation Model (DEM) and the use of Satellite images, integrating with GIS through the use of DEM (created) of the study area that will give a complete good dimension of watershed analysis of the study area, suggesting a new drainage patterns to minimize the flooding problems in and around the study area.

\section{METHODOLOGY}

The research work based on Remote Sensing and GIS functionality in solving environmental hazards particularly flooding and erosion hazards. Watershed analysis was used in GIS environment to undertake suitable drainage pattern selection. DEM used in the project was generated using a contour interpolation from point (ordinary kriging) method, the special coordinates of the points were captured using ground survey by the use of Total Station (Theodolite). Topographical map covering the case study area at a scale of 1:50,000 was acquired and a point on the contour line $750 \mathrm{ft}(228.6 \mathrm{~m})$ that passed through the study area was marked and it coordinates were interpolated from the topographic sheet as 226382.344mE, 1033471.435mN using a hand held GPS, the point was set out on the ground which was in turned served as the control for both the $3 D(E, N, Z)$ data capture using a South Total Station. Those 3D coordinates of the scattered points within the study area was then used in ILWIS software environment to interpolate the contour lines using interpolation from points by simple kriging method. Then the required Digital Elevation Model (DEM) of the study area was generated.

\section{INSTRUMENTS USED}

\section{SOFTWARE}

The software used in this research study includes:

i. Integrated Land and Water Information System (ILWIS) version 3.1 and 3.3 Academic.

ii. CorelDRAW suites 12.

iii. AutoCAD version 2010.

iv. Windows 7 professional operating system for computer. 


\section{DATA PROCESSING}

The plotting of ground survey data in AutoCAD 2010 software, the horizontal geometry of the acquired spatial data using Total Station was plotted in AutoCAD 2010 Version. Details plotted include points from which the contour lines were generated where by the height values were inputted when the drawing was exported in to ILWIS software in Drawing exchange Files (.DXF) format. Other details plotted include the existing drainage within the study area.

The second procedure was creating digital elevation model (DEM). DEM can be generated through the following techniques: digital photogrammetry, satellite imagery, point interpolation etc. (Musa. 2007). Point interpolation of contour lines by Ordinary Kriging method in ILWIS software environment was used in this research work. This procedure involves

1. Creating of point map. The point map was created in ILWIS 3.3 software environment by importing AutoCAD drawing exchange file (DXF), file containing the surveyed points and were giving a Value Domain. The points were edited in such a way that their respective height values were imputed on to each point. Then the contour interpolation where by the edited point map used in the contour interpolation using Simple kriging method, with a precession of $0.001 \mathrm{~m}$, a vector layer for existing drainages was created. The spatial data obtained from the ground survey method was used in the production of the vector layer map. The coordinates were used in plotting the drainage geometry and delineation in AutoCAD 2010 software environment which was letter exported to ILWIS environment as Drawing eXchange Files (.DXF) and saved as a segment map.

The slope and aspect maps were determined. They are created by the use of separate raster object for each of these terrain characteristics in the ILWIS 3.3 software environment as follows: the height in X-direction was calculated and height in Y-direction was also calculated. The slope map in percentage was calculated from maps DX and DY.

Thus:

SLOPEPCT $=100$ * HYP(DX,DY)/ PIXSIZE(DEM)

To convert the percentage values into degrees, type:

SLOPEDEG = RADDEG(ATAN(SLOPEPCT/100))

To calculate a classified aspect map, the following expressional procedure was followed:

ASPECTR = ATAN2(DX,DY) + PI

To convert the radians into degrees, the following expression was typed:

ASPECTD $=$ RADDEG $(($ ASPECTR $))$
The watershed map refers to the flow accumulation map and its operation performs a cumulative count of the number of pixel that naturally drains into outlets. The operation can be used to find the drainage pattern of a terrain.

\section{ANALYSIS AND DISCUSSIONS OF RESULTS}

The research work explained the steps employed to minimize flooding and erosion hazards in sangere of Girei Local Government Area in Adamawa State; it use the area based analysis, and was achieved by designing the digital elevation model (DEM) covering the study area; determine the fill DEM and finally delineating the watershed of the study area using area based analysis for watershed in an Integrated Land and Water Information system (ILWIS) 3.1 and 3.3 Academic Software environment.

Fig. 1 is the buildup map used in this research during overlay operations in order to use the road networks in between the buildup areas to serve as surrogate for the suitable drainage networking.

Fig.2 is satellite image of the study area from which the buildup area was digitized: it consists of two fully georeference satellite image glued together to form a single image covering the same area. It provides the current detail information within the study area.

Fig. 3 shows the digital elevation model obtained as a result of contour interpolation from point height values by the use of ordinary kriging method. it was used in this research work for the creation of aspect map (fig.4) and slope map (fig.5). Watershed map (fig.6) and the hydrological analysis that produced optimal drainage map (fig.7). 


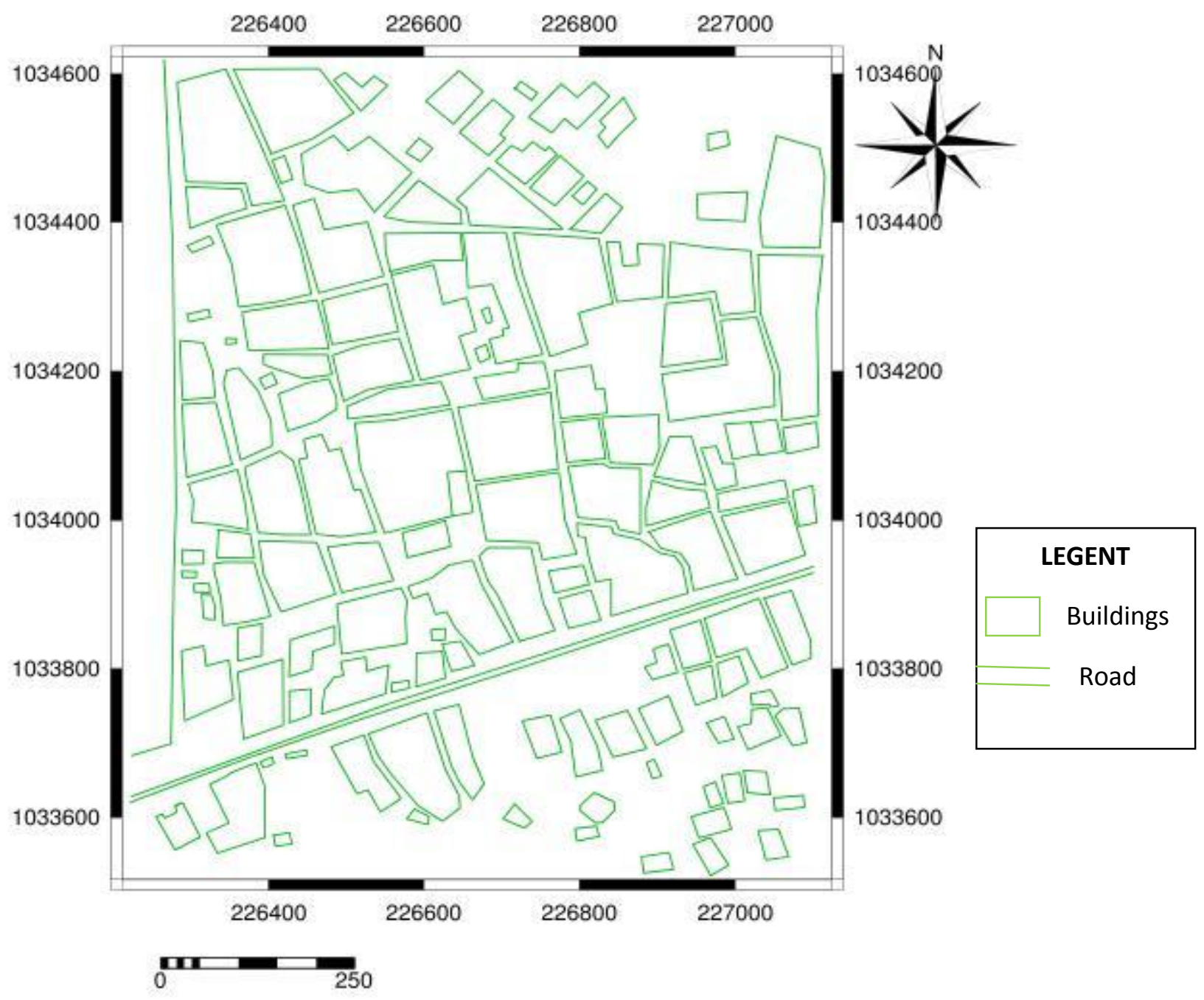

Fig. 1: Map of the Study Area Showing Buildup Area. 


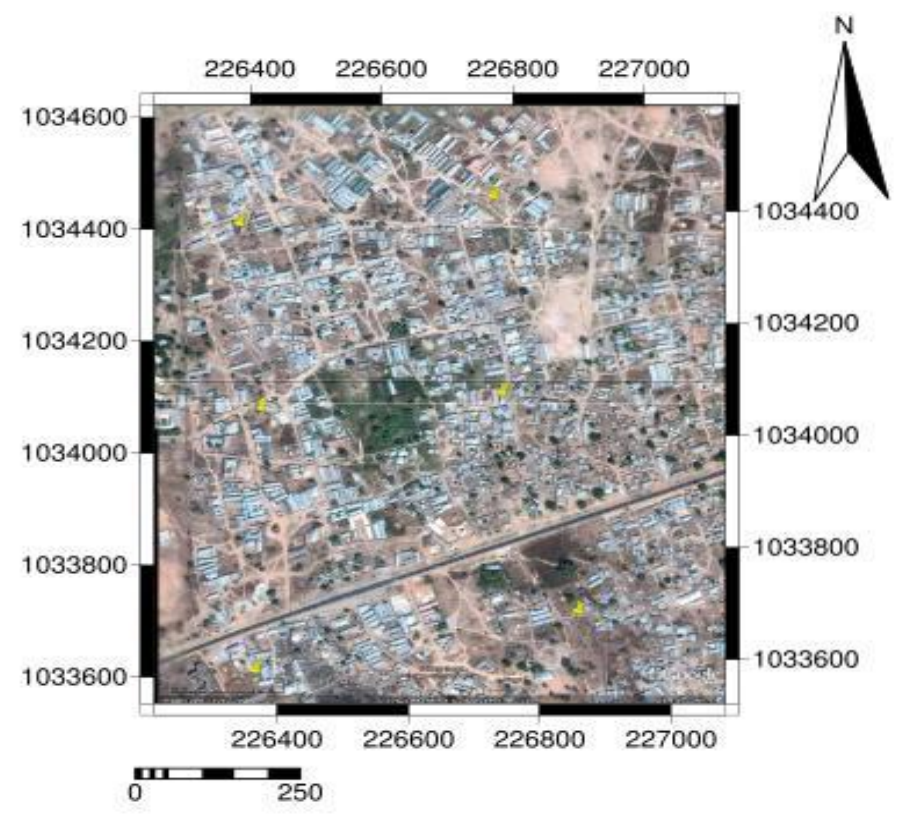

Fig. 2: Map Showing Satellite Image of the Study Area.

Source: (Google Earth, 2010) 


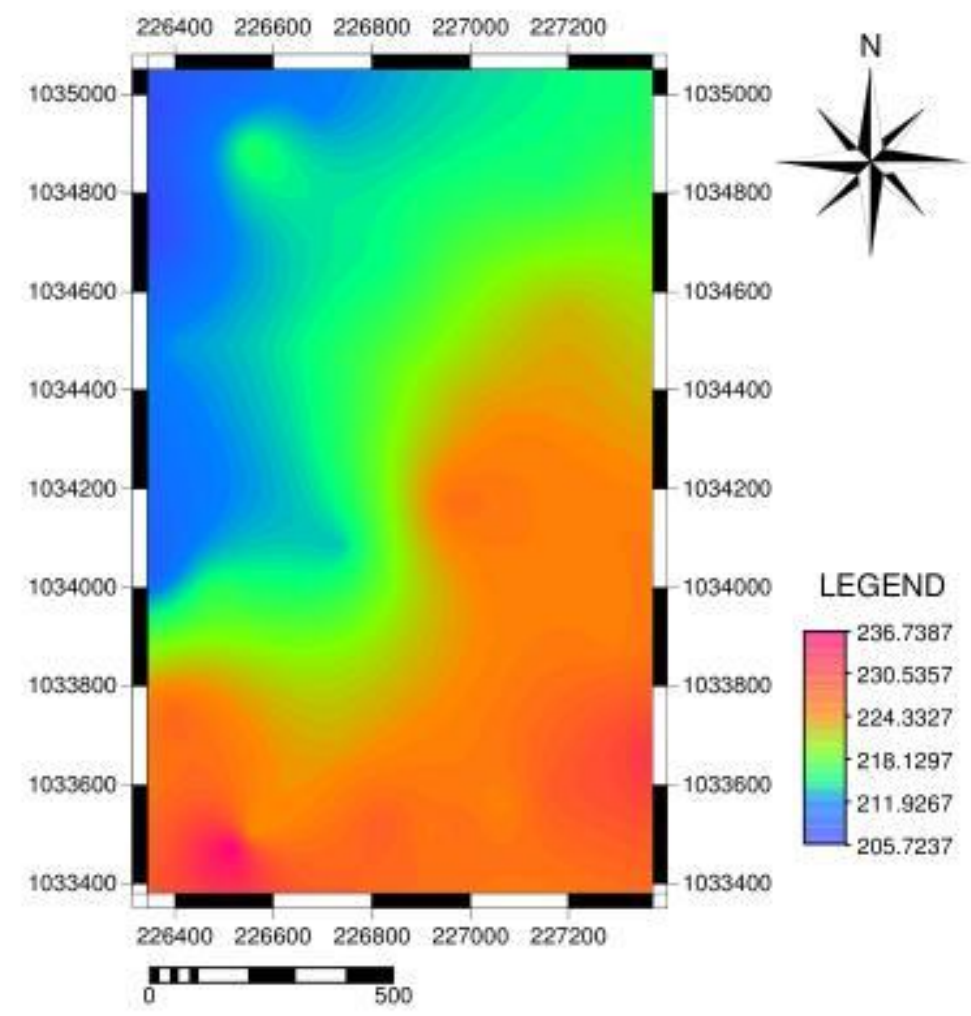

Fig. 3: Map Showing the DEM of the Study Area. 


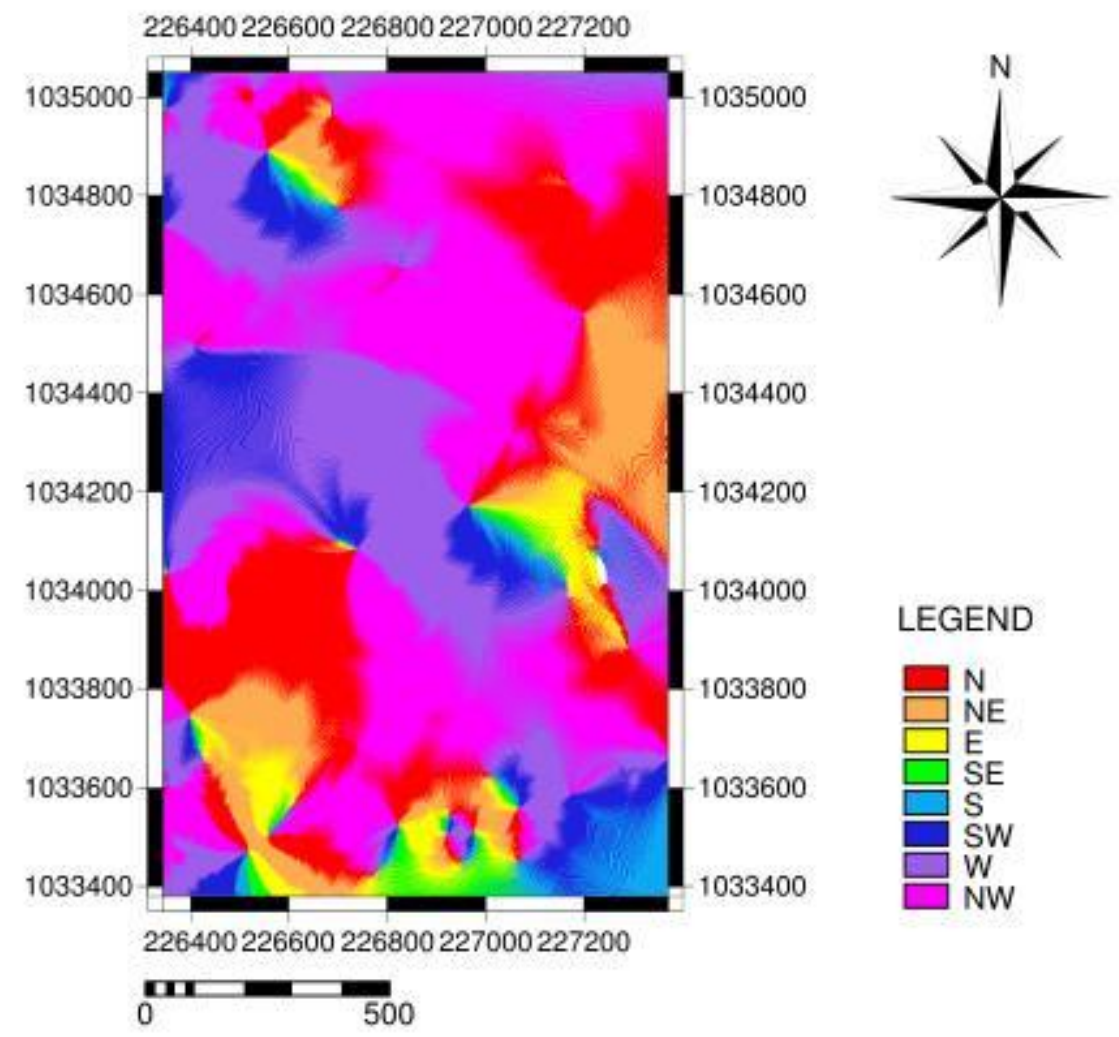

Fig.4: Aspect Map of the Study area 


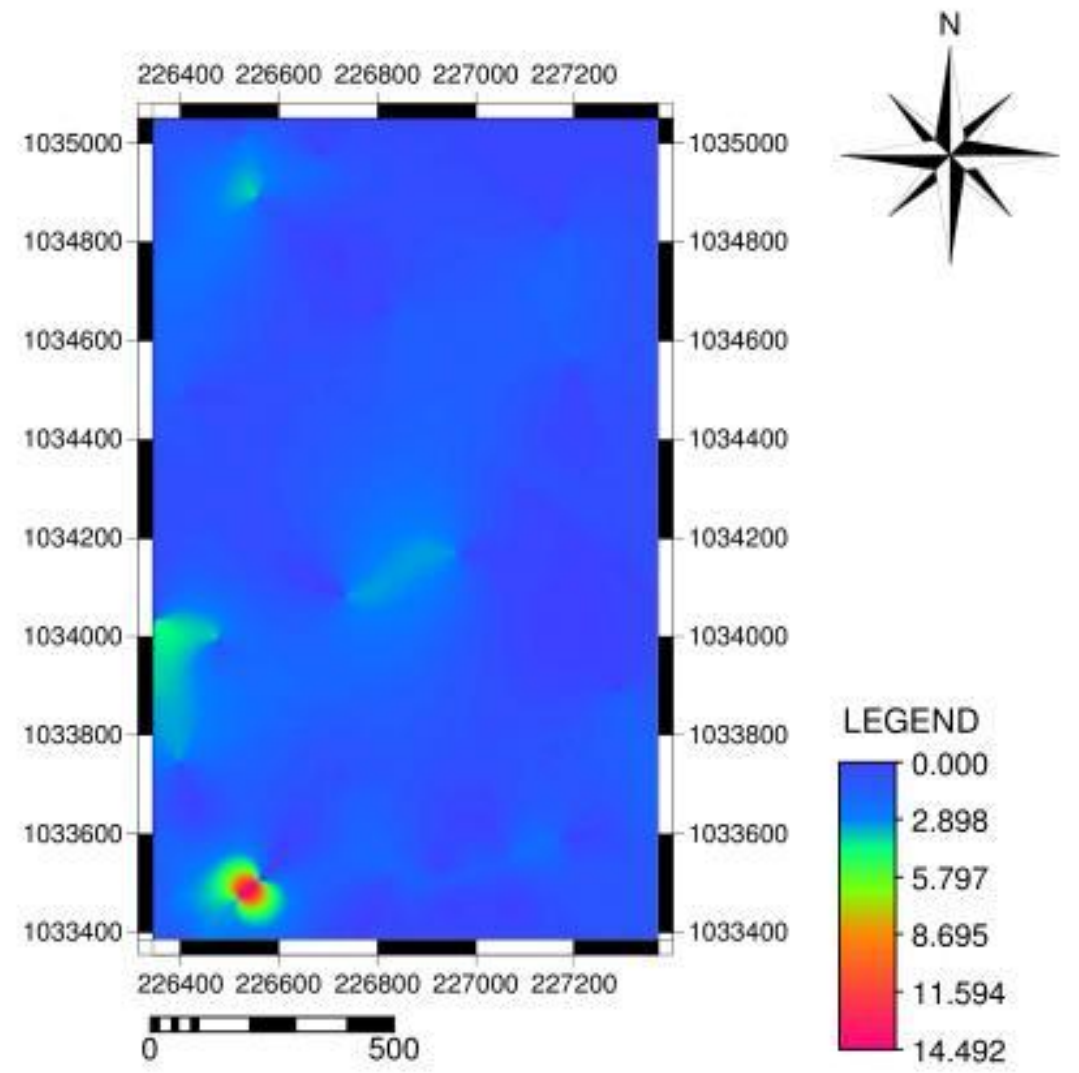

Fig. 5: Slope Map of the Study Are: 


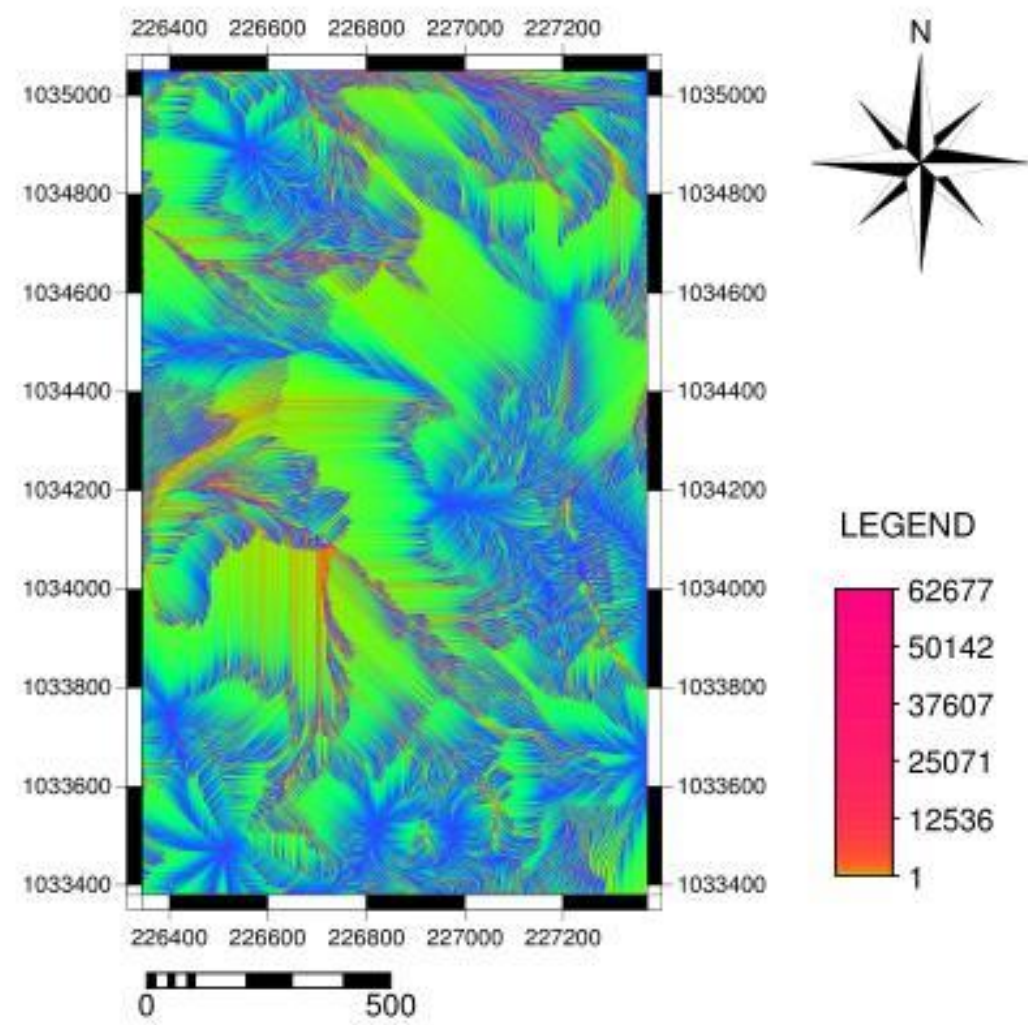

Fig. 6: Watershed Map of the Study Area. 


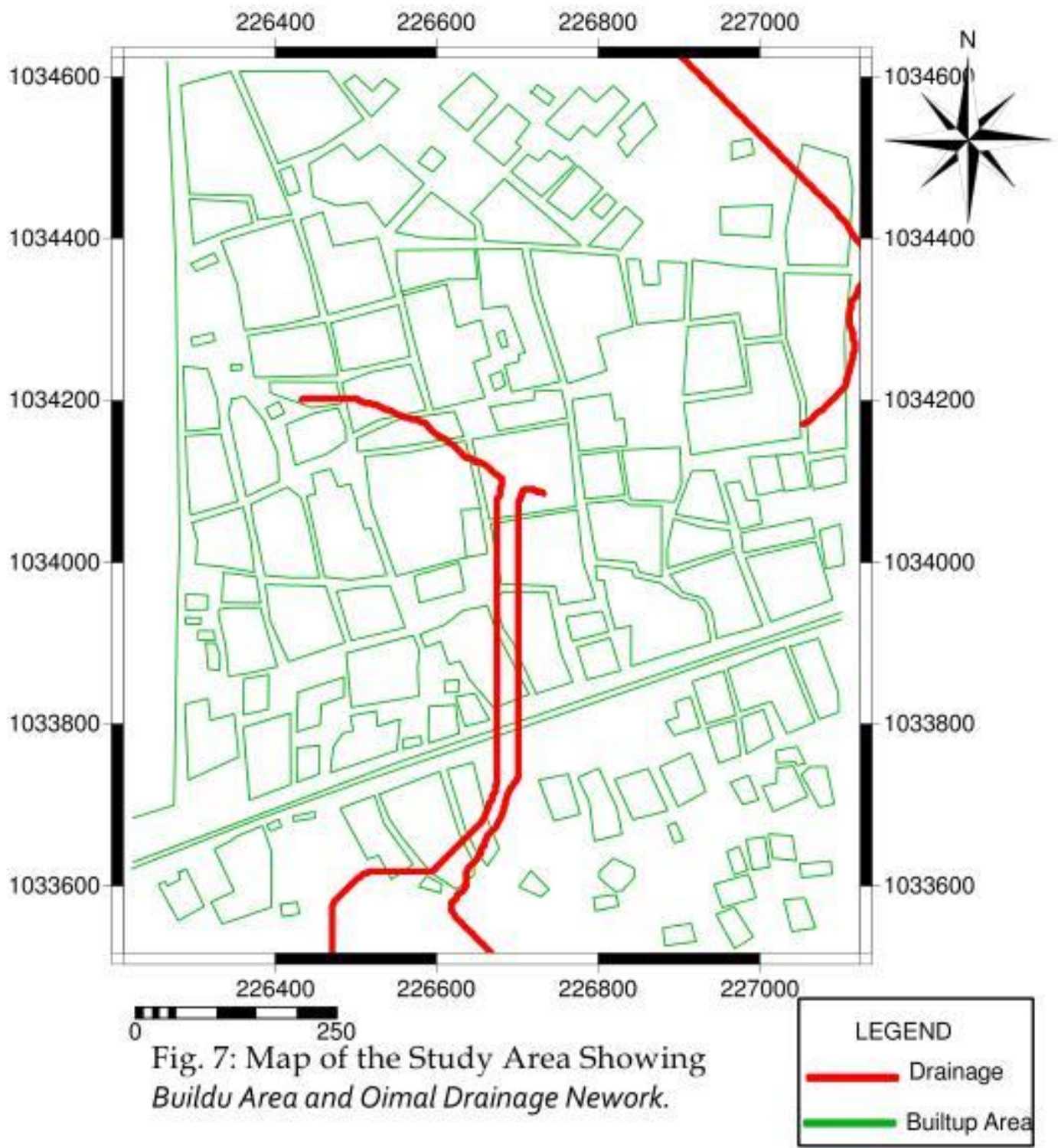




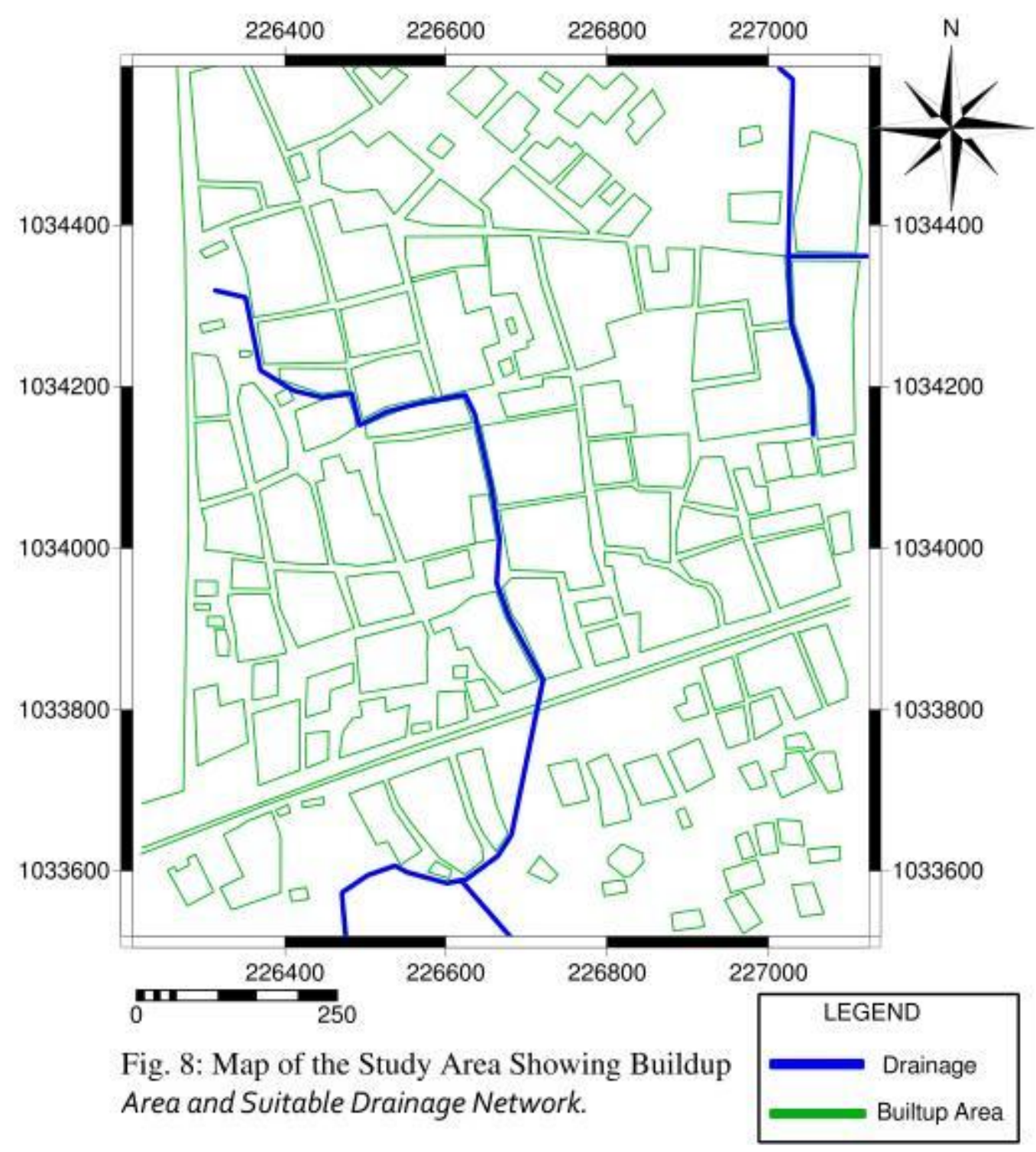

As shown in fig. 3, the study area is lying on an undulated terrain with the peak area to the south-west and low area to the north-west. The analysis resulted into two alternative drainage networks, the optimal drainage network (fig.7) which requires demolition of some buildup areas but will yield the most probable solution to the hydrological problem (erosion and flooding) in the study area, and the suitable drainage network (fig.8) that will avoid demolition of buildup area by using road network as surrogate but will not produce better solution than the optimal one.

Whichever network chosen, the width of the drainage to the southern part should not be less than $2 \mathrm{~m}$ and $2.5 \mathrm{~m}$ for drainages in the northern part of the area, considering the effect of flow accumulation as shown in fig.6.

The research work was done in GIS environment where by maps, such as those showing the 
buildup area, the Dem, the slope and the Aspect maps, the watershed map, the optimal and suitable drainage network map of the study area were all generated. In achieving the above, involve ground survey techniques, and remote sensing data acquisition systems integrated in GIS environment was used; the analysis tries to find out a means that if fully implement will minimize the effect of flooding and erosion hazards in the study area through the implementation/construction of drainage network as shown in fig.7 and fig.8. Base on this research work, it recommends the following.

i. Watershed analysis is recommended for the determination of optimal drainage and suitable drainage patterns within a given area.

ii. There is an urgent need, to come to the aid of those residing in Sangere area, by constructing the drainage networks before flooding and erosion destroy the already damage environment.

iii. There should be a planned layout design to avoid the negative effects of unplanned layout (such as flooding and erosion)

\section{REFERENCES}

Akintola, F. O., 1978. Hydrological consequencies of urbanization. A case study of urban city. Pp151

Bhaskar, k. and Krishna., 2004. Flooding and flash floods. Hhp://www.wiki.png/flood, Wikipedia.

Charley, R. J., 1989. Introduction to physical hydrology, Methuen London.
Datta, M. M., 2003. New area of GIS application.

Dodson and Li., 1999. The accuracy and efficiency of GIS based flood plain determination. Oxford University Press, New York.

Ishaku J. N., 2011. Assesment of groundwater quality index for Jimeta-Yola area, Northeastern Nigeria. A journal of Geology and Mining Research Vol. 3(a) http://www.academicjournals.org/JGMR last access $4^{\text {th }}$ Dec. 2011 at 9:00am

John T. Watson, Michelle Gayer and Marine A. Connolly., 2012. Epidemic after natural disaster. A Journal of Emerging Infectious Diseases (EID) http://www.nc.cdc.gov/ed/r/13/1/1.htm last access $4^{\text {th }}$ Dec. 2011 at 11:00am

Kang-tsungchang., 2003. Introduction to Geographic Information System. Tata Mc Graw Publishers.

Mazunder, S. K., 1983. Digital technology in surveying and mapping Principles, Applications and Legislative Issues. Rhyce Keree Publishers, Enugu, Nigeria. Pp23

Musa A. A., 2007. Application of GIS in the planning field. A paper presented at the department of Urban and Regional Planning MauTech. Yola

Wister and Brater., 1996. Hydrology; John Wileri, London $2^{\text {nd }}$ edition. 